\title{
Direct Power Control of a DFIG Fed by a Seven- Level Inverter Using SVM Strategy
}

\author{
Habib BENBOUHENNI \\ Electrical Engineering department, National Polytechnique School of Oran Maurice Audin, Oran, Algeria \\ (habib0264@gmail.com) \\ $\$$ Corresponding Author; Habib Benbouhenni, BP: 50B Ouled Fares Chlef, Algeria, Tel: +213663956329, \\ habib0264@gmail.com
}

Received: 21.04.2019 Accepted:30.05.2019

\begin{abstract}
In this paper, a direct power control (DPC) is applied to a DFIG (doubly fed induction generator) based wind power conversion systems (WPCSs). The DPC with seven-level space vector modulation (7L-SVM) strategy reduces the harmonic distortion of voltage/current and powers ripples compared with the conventional DPC control scheme; this advantage reduces the ripples of the electromagnetic torque, active and reactive powers. Combined with the DPC technique, the system behavior will present a fast response time, which will guarantee a good tracking of the reference signal. The enhanced performances brought by this strategy are studied in the simulation results.
\end{abstract}

Keywords: DFIG, DPC, WPCSs, 7L-SVM.

\section{Introduction}

DPC control scheme using switching table and hysteresis comparators is the traditional strategy used for DFIG-based WPCSs. This strategy is similar to direct torque control (DTC). Major advantages of DPC control scheme are as follows: simple control scheme, fast response time, easy to implement and less dependence on DFIG parameters [1]. The basic idea of the traditional DPC strategy is a direct control of the active and reactive powers of the DFIG without any internal control loop or pulse width modulation technique [2].

In this paper, the DPC strategy with the application of the seven-level SVM strategy has been considered. The original contribution of this paper is the application of the 7L-SVM technique in the DPC control with doubly fed induction generator and simulation investigation of this proposed control scheme.

This paper is divided into seven sections. In Section 1, the introduction is presented. In Section 2, the mathematical model of the DFIG is described. The seven-level SVM technique has been discussed in Section 3. In Section 4, the description of the DPC strategy is presented. Section 5 deals with the description of the DPC strategy with the application of 7L-SVM strategy. simulation studies are presented and discussed in Section 6. The paper is concluded with a short conclusion.

\section{The DFIG model}

The doubly fed induction generator is described in the Park $q$ - $d$ frame by the following set of equations [3, 4].

Stator flux:

$$
\left\{\begin{array}{l}
\psi_{d s}=L_{s} I_{d s}+M I_{d r} \\
\psi_{q s}=L_{s} I_{q s}+M I_{q r}
\end{array}\right.
$$

Where: $\Psi_{\mathrm{qs}}$ and $\Psi_{\mathrm{ds}}$ is the stator fluxes.

$\mathrm{L}_{\mathrm{s}}$ is the inductance of the stator

$I_{d s}$ and $I_{q s}$ are the stator currents

$\mathrm{M}$ is the mutual inductance

$\mathrm{I}_{\mathrm{dr}}$ and $\mathrm{I}_{\mathrm{qr}}$ are the rotor currents

Rotor flux:

$\left\{\begin{array}{l}\psi_{d r}=L_{r} I_{d r}+M I_{d s} \\ \psi_{q r}=L_{r} I_{q r}+M I_{q s}\end{array}\right.$

Where: $\Psi_{\mathrm{dr}}$ and $\Psi_{\mathrm{qr}}$ is the rotor fluxes

$\mathrm{L}_{\mathrm{r}}$ is the inductance of the rotor

Stator voltage: 


$$
\left\{\begin{array}{l}
V_{d s}=R_{s} I_{d s}+\frac{d}{d t} \psi_{d s}-\omega_{s} \psi_{q s} \\
V_{q s}=R_{s} I_{q s}+\frac{d}{d t} \psi_{q s}+\omega_{s} \psi_{d s}
\end{array}\right.
$$

Where: $\mathrm{V}_{\mathrm{ds}}$ and $\mathrm{V}_{\mathrm{qs}}$ are the stator Voltages

$\mathrm{R}_{\mathrm{s}}$ is the stator resistance

$\omega_{s}$ : is the electrical pulsation of the stator.

Rotor voltage:

$$
\left\{\begin{array}{l}
V_{d r}=R_{r} I_{d r}+\frac{d}{d t} \psi_{d r}-\omega_{r} \psi_{q r} \\
V_{q r}=R_{r} I_{q r}+\frac{d}{d t} \psi_{q r}+\omega_{r} \psi_{d r}
\end{array}\right.
$$

Where : $\mathrm{V}_{\mathrm{dr}}$ and $\mathrm{V}_{\mathrm{qr}}$ are the rotor voltages

$\mathrm{R}_{\mathrm{r}}$ is the rotor resistance

The stator side reactive and active powers are defined as:

$$
\left\{\begin{array}{l}
P_{s}=\frac{3}{2}\left(V_{d s} I_{d s}+V_{q s} I_{q s}\right) \\
Q_{s}=\frac{3}{2}\left(V_{q s} I_{d s}-V_{d s} I_{q s}\right)
\end{array}\right.
$$

Where: $P_{s}$ is the active power

$\mathrm{Q}_{\mathrm{s}}$ is the reactive power.

The electrical model of the DFIG is completed by the following mechanical equation:

$$
T_{e}-T_{r}=J \cdot \frac{d \Omega}{d t}+f \cdot \Omega
$$

Where: $\Omega$ is the mechanical rotor speed.

$\mathrm{T}_{\mathrm{e}}$ is the electromagnetic torque

$J$ is the inertia

$f$ is the viscous friction coefficient

$T_{r}$ is the load torque.

The electromagnetic torque can be written as follows:

$T_{e}=\frac{3}{2} p \frac{M}{L_{r}}\left(I_{d r} \cdot \psi_{q s}-I_{q r} \cdot \psi_{d s}\right)$

Where: $p$ is the number of pole pairs.

\section{Seven-level SVM strategy}

Traditionally the SVM technique is widely used in control of machine drives. In this strategy is need to calculate the sector and angle. In addition, this strategy is difficult to implement. In [5], the author propose an new SVM algorithm based on calculating the maximum (Max) and minimum (Min) of three-phase voltages. This proposed SVM method is simple and easy to implement compared to classical SVM strategy. In [6], the author propose a five-level SVM strategy to control the inverter of DFIG. The SVM strategy of the four-level inverter is proposed in [7]. This paper presents a SVM modulation scheme of seven-level NPC inverter. Fig. 1 shows the SVM technique of seven-level NPC inverter. It is observed that the proposed strategy is simple control and easy to implement. This proposed SVM strategy can be minimized the harmonic distortion of the voltage/current and electromagnetic torque ripple of the DFIG-based WPCSs. On the other hand, the seven-level SVM strategy based on the following steps:

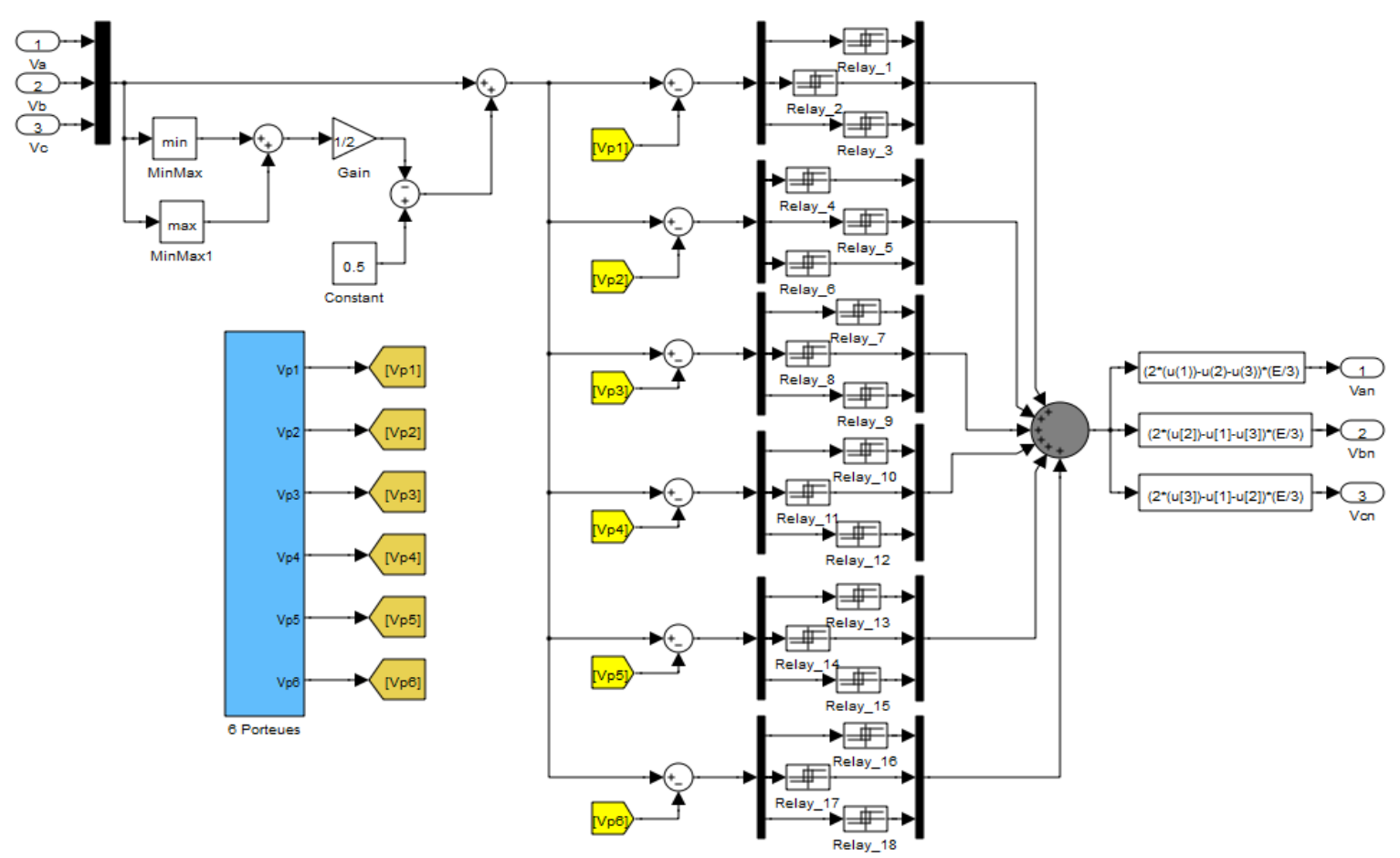

Fig. 1. Block diagram of seven-level SVM strategy. 
- Calculates the minimum voltages (min (Va, Vb, $\mathrm{Vc})$ )

- Calculates the maximum voltages $(\max (\mathrm{Va}, \mathrm{Vb}$, $\mathrm{Vc})$ )

- Add the maximum and minimum voltages (max $(\mathrm{Va}, \mathrm{Vb}, \mathrm{Vc})+\min (\mathrm{Va}, \mathrm{Vb}, \mathrm{Vc}))$.

- The last step is to compare step-3 waveforms with $\mathrm{Vp} 1\left(\mathrm{~V}_{\text {Triangle }}\right)$ to $\mathrm{Vp}$ 6, and generates the pulses for that switch presents in the three-phase voltage source converter circuit.

\section{Classical DPC control}

The DPC goal is to control the reactive and active powers of the DFIG-based wind turbine systems (WTSs). In this strategy the active and reactive powers that are directly controlled [8]. The traditional DPC, which is designed to control stator reactive and active powers of the DFIG, is shown in Fig. 2 [9].

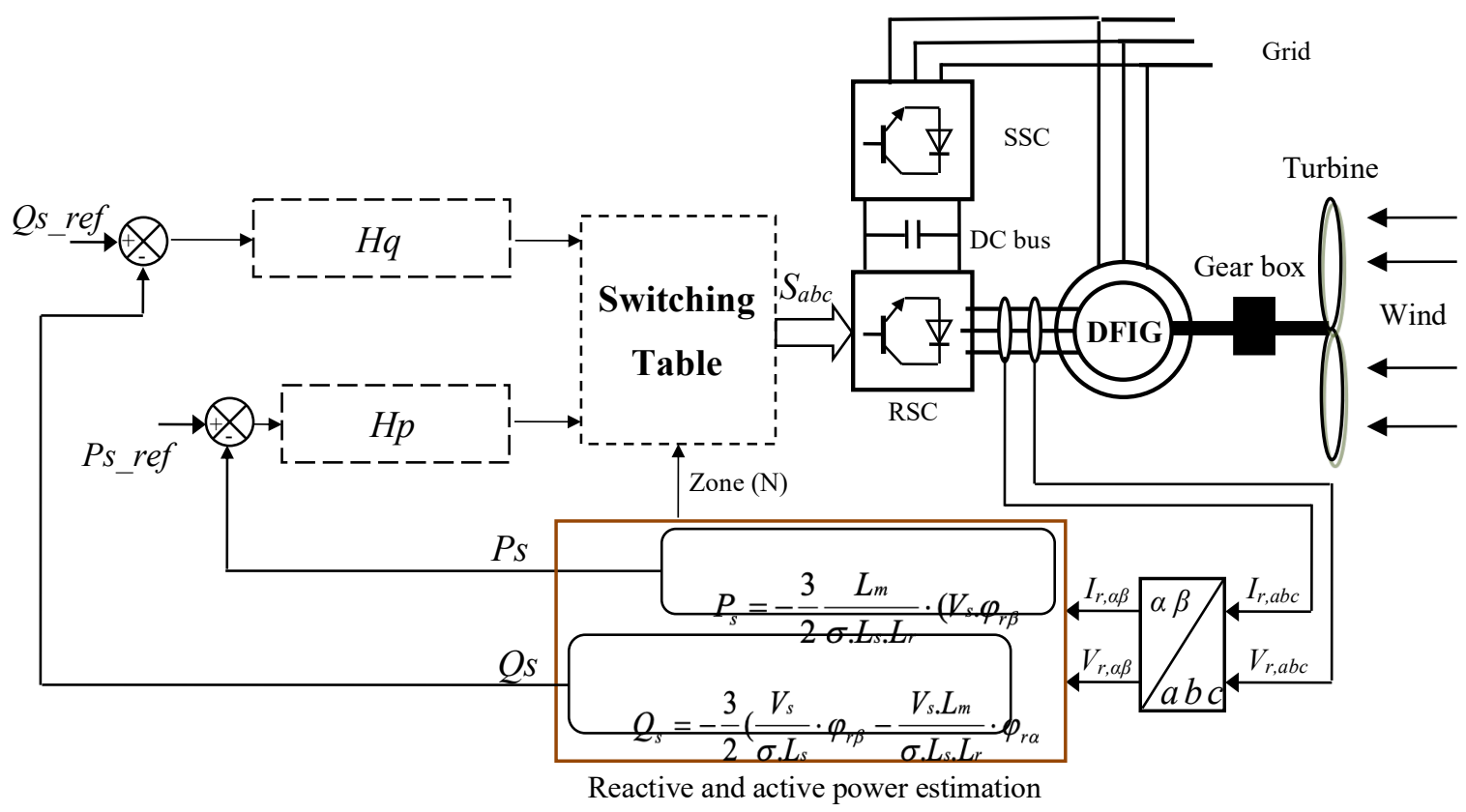

Fig. 2. Conventional DPC strategy.

Rotor flux is estimated using (8) and (10) [10].

$\Psi_{r \beta}=\sigma L_{r} I_{r \beta}$

Where : $\Psi_{\mathrm{r} \beta}$ : is the rotor flux linkage of $\beta$-axis.

$I_{\mathrm{r} \beta}$ : is the rotor current linkage of $\beta$-axis.

And :

$\sigma=1-\frac{M^{2}}{L_{r} L_{s}}$

$\Psi_{r \alpha}=\sigma L_{r} I_{r \alpha}+\frac{M}{L_{s}} \Psi_{s}$

Where : $\Psi_{\mathrm{r} \alpha}:$ is the rotor flux linkage of $\alpha$-axis.

$\Psi_{\mathrm{s}}$ is the stator flux.

$\mathrm{I}_{\mathrm{r} \alpha}$ : is the rotor current linkage of $\alpha$-axis.

The stator flux amplitude is given by:

$$
\Psi_{s}=\sqrt{\Psi_{s \alpha}^{2}+\Psi_{s \beta}^{2}}
$$

Where: $\Psi_{\mathrm{s} \alpha}$ : is the stator flux linkage of $\alpha$-axis.

$\Psi_{\mathrm{s} \beta}$ : is the stator flux linkage of $\beta$-axis.

And :

$\left|\overline{\Psi_{s}}\right|=\frac{\left|\overline{V_{s}}\right|}{w_{s}}$

Where : $\mathrm{V}_{\mathrm{s}}$ is the stator voltage.

Reactive and active powers is estimated using (13) and (14) $[11,12]$.

$Q_{s}=-\frac{3}{2}\left(\frac{V_{s}}{\sigma \cdot L_{s}} \cdot \psi_{r \beta}-\frac{V_{s . L_{m}}}{\sigma \cdot L_{s} \cdot L_{r}} \cdot \psi_{r \alpha}\right)$

$P_{s}=-\frac{3}{2} \frac{L_{m}}{\sigma \cdot L_{s} \cdot L_{r}} \cdot\left(V_{s .} \psi_{r \beta}\right)$

Where: $\mathrm{Lm}$ is the mutual inductance 
In conventional DPC control scheme a three-level hysteresis comparator (Fig. 4) is used for the stator active power (Hp) and a two-level hysteresis comparator (Fig. 5) for the reactive power $(\mathrm{Hq})$. On the other hand, based on the values of constants $\mathrm{Hp}$ and $\mathrm{Hq}$ and the position of the rotor flux , the inverter switching algorithm is as shown in Table 1.

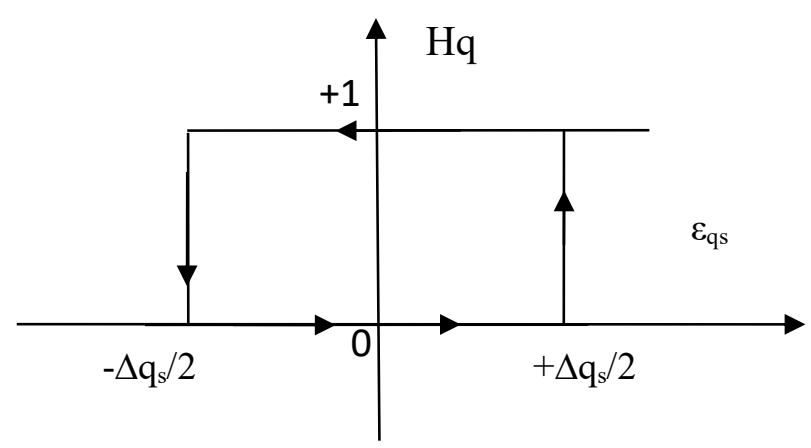

Fig. 3. Reactive power hysteresis comparator.



Fig. 4. Active power hysteresis comparator.
Table 1. Switching table for traditional DPC strategy

\begin{tabular}{|c|c|c|c|c|c|c|c|}
\hline \multicolumn{2}{|c|}{$\mathbf{N}$} & $\mathbf{1}$ & $\mathbf{2}$ & $\mathbf{3}$ & $\mathbf{4}$ & $\mathbf{5}$ & $\mathbf{6}$ \\
\hline Hq & $\mathbf{H p}$ & & & & & & \\
\hline \multirow{3}{*}{$\mathbf{1}$} & $\mathbf{1}$ & 5 & 6 & 1 & 2 & 3 & 4 \\
\cline { 2 - 8 } & $\mathbf{0}$ & 7 & 0 & 7 & 0 & 7 & 0 \\
\cline { 2 - 8 } & $\mathbf{- 1}$ & 3 & 4 & 5 & 6 & 1 & 2 \\
\hline \multirow{3}{*}{$\mathbf{0}$} & $\mathbf{1}$ & 6 & 1 & 2 & 3 & 4 & 5 \\
\cline { 2 - 8 } & $\mathbf{0}$ & 0 & 7 & 0 & 7 & 0 & 7 \\
\cline { 2 - 8 } & $-\mathbf{1}$ & 2 & 3 & 4 & 5 & 6 & 1 \\
\hline
\end{tabular}

\section{DPC with 7L-SVM strategy}

In order to improve the traditional DPC control performances a complimentary use of seven-level SVM strategy is proposed. This proposed control scheme reduced harmonic distortion of stator voltage/current, electromagnetic torque ripples, reactive and active ripples compared to classical DPC strategy. This proposed control is simple and easy to implement. The proposed seven-level DPC-SVM control scheme designed to control the stator active and reactive powers of the DFIG system is illustrated in Fig. 5.

The PI controller gains ( $\mathrm{Ki}$ and $\mathrm{Kp}$ ) were found after performing simulations in Matlab/Simulink software. Table 2 shows the constants values.

Table 2. PI controller gaines

\begin{tabular}{|l|c|}
\hline $\mathbf{K i}$ & 0.6 \\
\hline $\mathbf{K p}$ & 0.00005 \\
\hline
\end{tabular}

\section{Simulation results}

To study the performance of the proposed control strategies, seven-level DPC-SVM and classical DPC control scheme, the simulation of the system was conducted using Matlab/Simulink software.



Fig. 5. Block diagram of seven-level DPC-SVM control.

iMW, 380/690V, 
two poles, $50 \mathrm{~Hz}$, with the following parameters : $\mathrm{Rs}=0.012 \Omega, \mathrm{Rr}=0.021 \Omega, \mathrm{Ls}=0.0137 \mathrm{H}, \mathrm{Lr}=0.0136 \mathrm{H}$, $\mathrm{M}=0.0135 \mathrm{H}$.

The system has the following mechanical parameters : $\mathrm{J}=1000 \mathrm{Kg} \cdot \mathrm{m}^{2}, \mathrm{fr}=0.0024 \mathrm{Nm} / \mathrm{s}$.

\section{A. Reference tracking test (RTT)}

From the simulation results presented in Fig. 6 and Fig. 7 it is apparent that the harmonic distortion (THD) of stator current for the seven-level DPC-SVM control is considerably minimized compared to classical DPC control scheme. Table 3 shows the comparative analysis of THD value for stator current.

Table 3. Comparative analysis of THD value

\begin{tabular}{|c|c|}
\hline DPC & Seven-level DPC-SVM \\
\hline $1 \%$ & $\mathbf{0 . 3 9 \%}$ \\
\hline
\end{tabular}

From the system responses given in Figs. 8-9 for DPC control and seven-level DPC-SVM strategy the reactive and active powers tracks the reference powers without overshoot, with zero steady state error. Fig. 10 shows the electromagnetic torque of DPC and proposed strategy.

From Figs. 11-13 can be seen that the proposed strategy minimized the torque ripples, stator active and reactive powers ripples compared to classical DPC strategy.
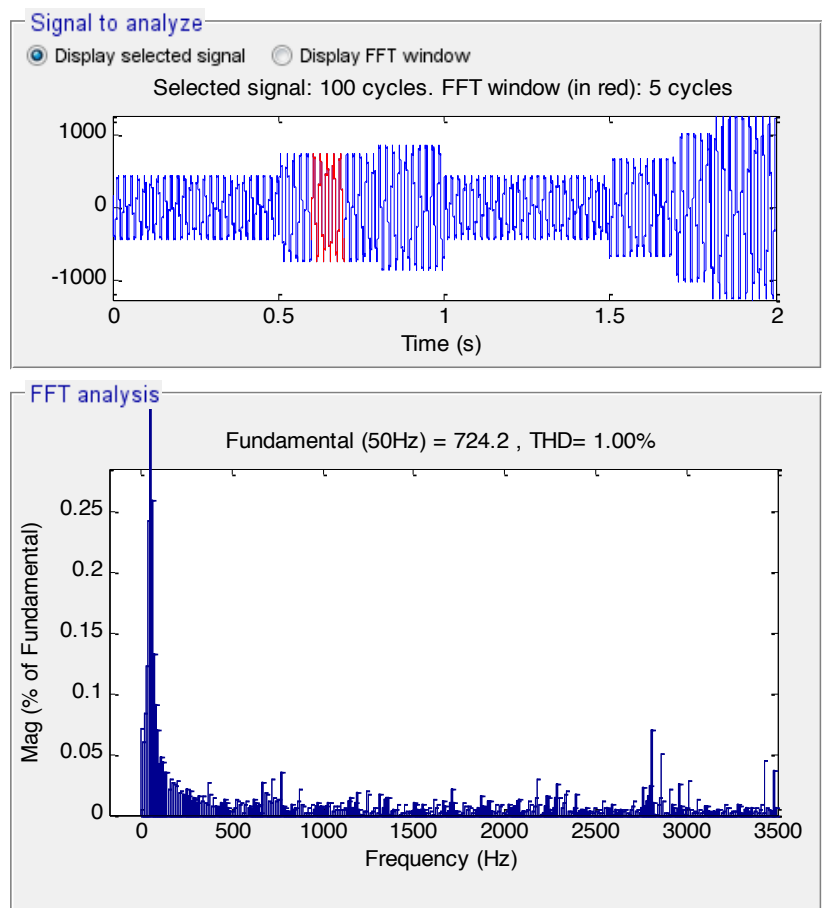

Fig. 6. Spectrum harmonic of rotor current (classical DPC).
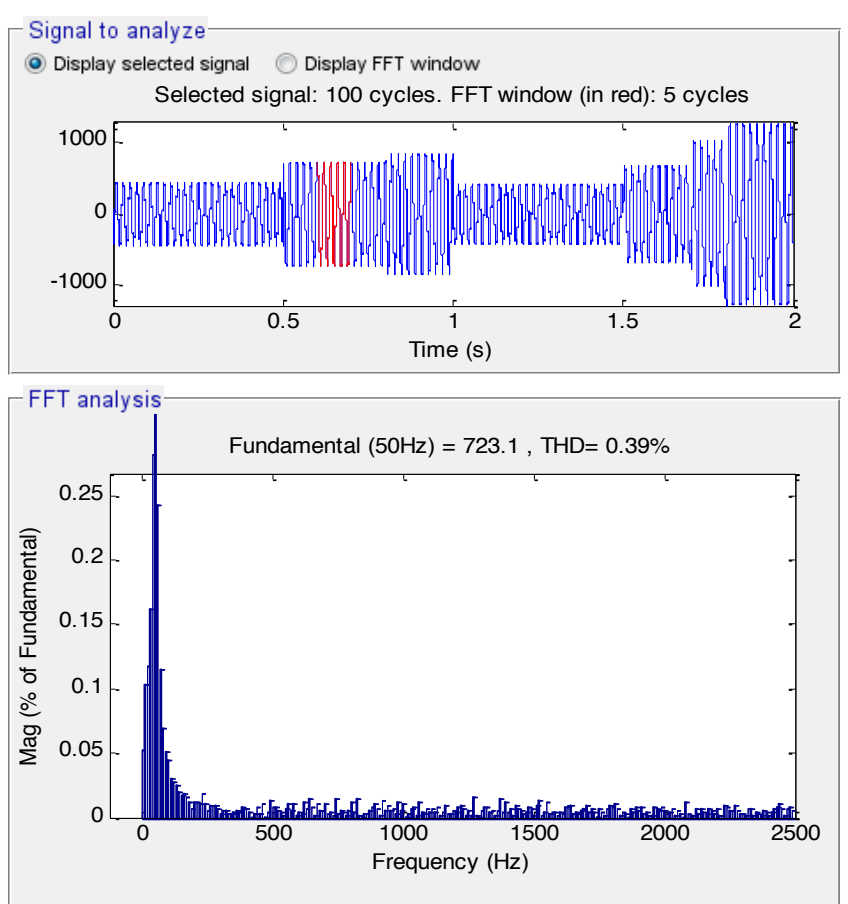

Fig. 7. Spectrum harmonic of rotor current (Seven-level DPCSVM)

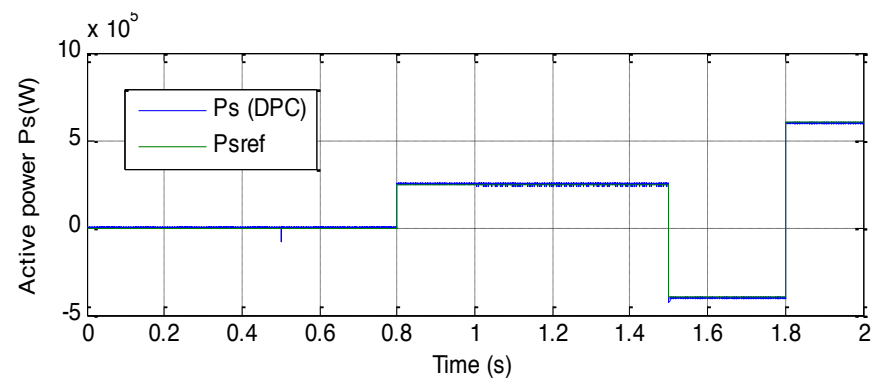

a)DPC

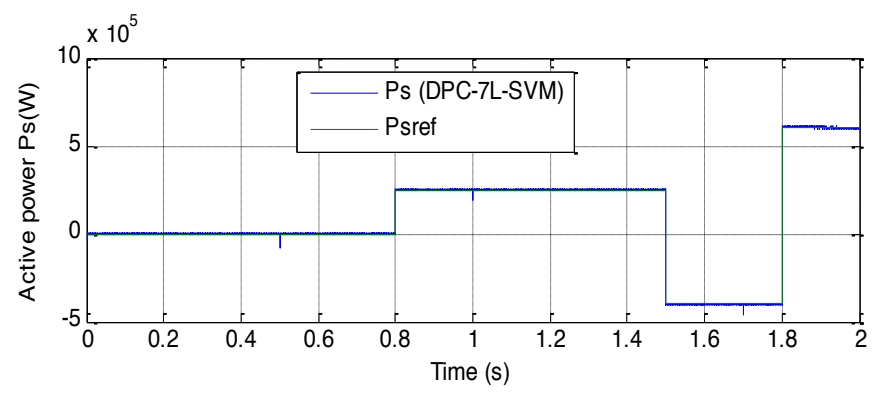

b) Seven-level DPC-SVM

Fig. 8. Active power (RTT). 
INTERNATIONAL JOURNAL Of SMART GRID

Habib Benbouhenni, Vol.3, No.2, June, 2019



a)DPC

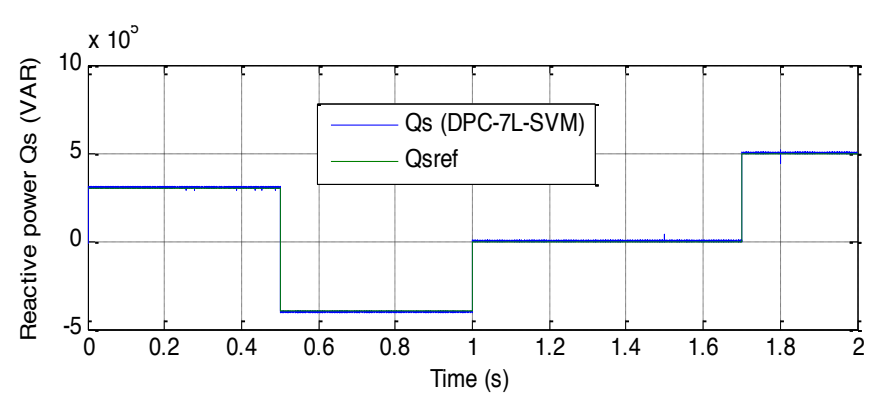

b)Seven-level DPC-SVM

Fig. 9. Reactive power (RTT).

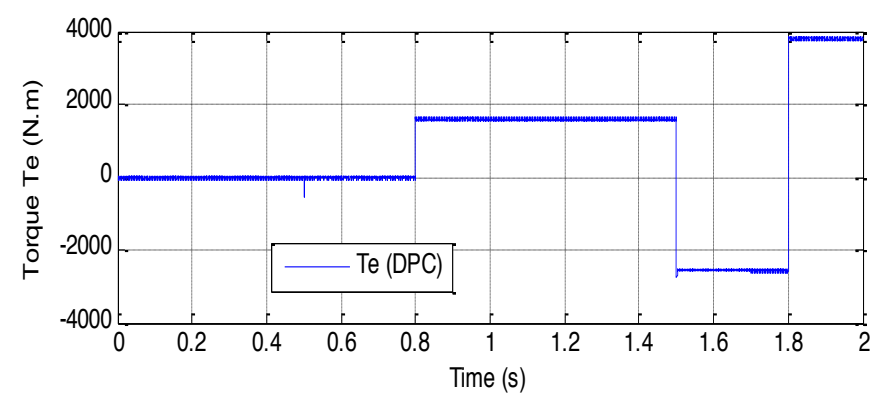

a)DPC

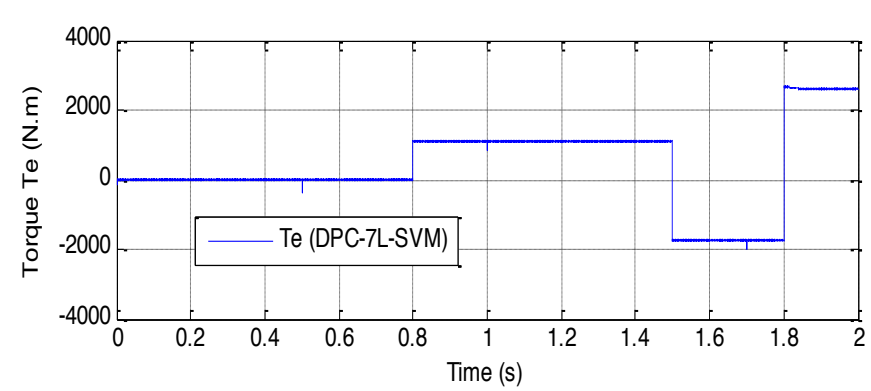

b)Seven-level DPC-SVM

Fig. 10. Torque (RTT).

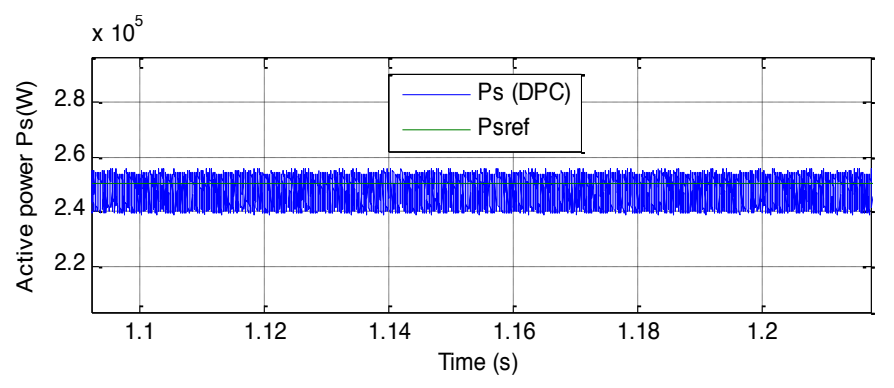

a)DPC

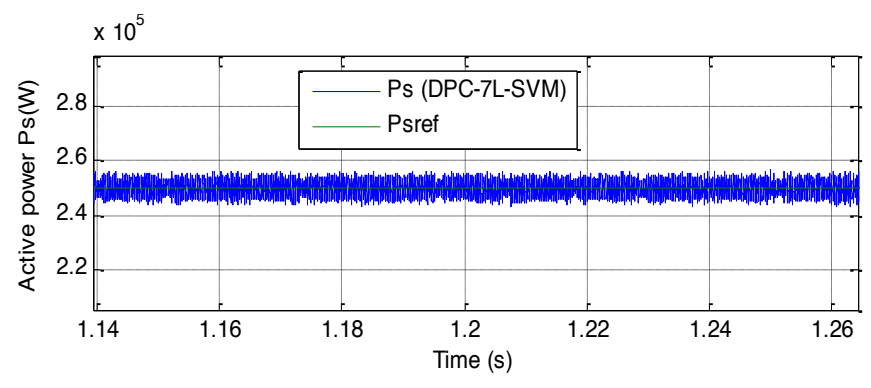

b)Seven-level DPC-SVM

Fig. 11. Zoom in the active power (RTT).

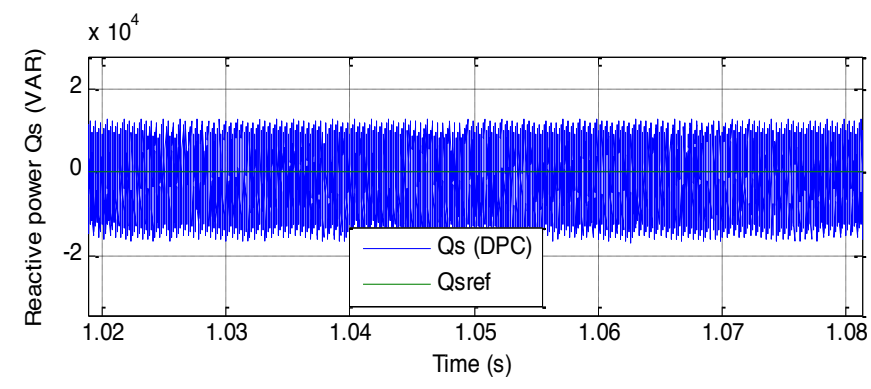

a)DPC

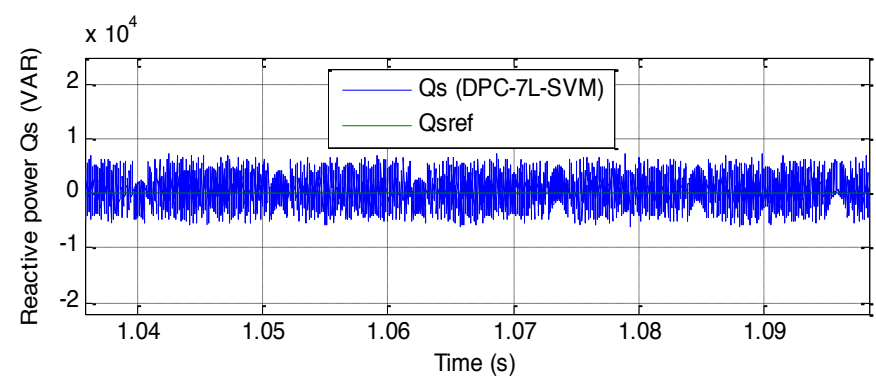

b)Seven-level DPC-SVM

Fig. 12. Zoom in the reactive power (RTT). 


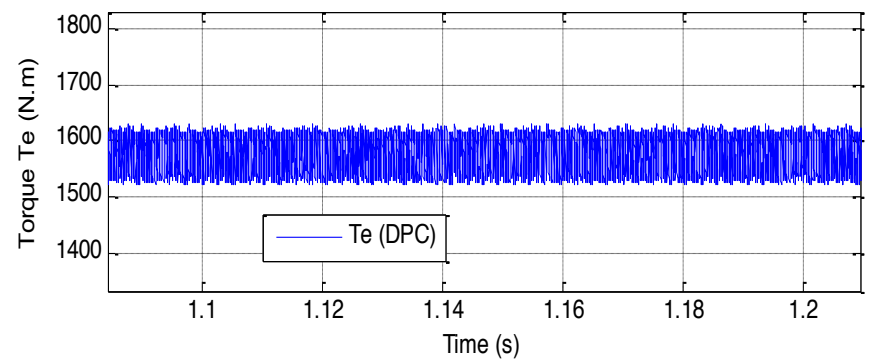

a)DPC

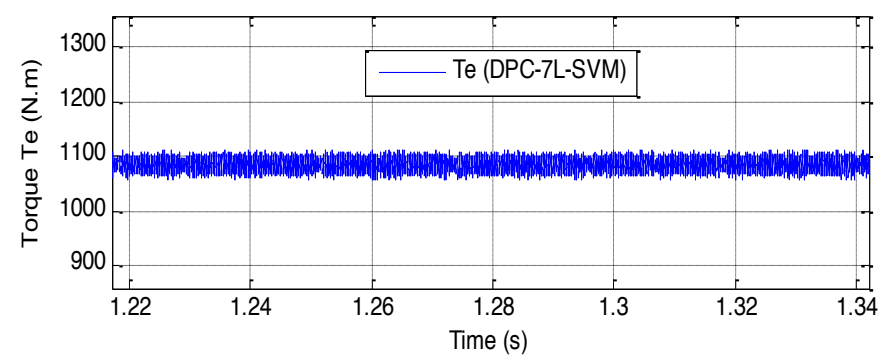

b)Seven-level DPC-SVM

Fig. 13. Zoom in the torque (RTT)

\section{B.Robustness Test(RT)}

In order to test the robustness of the proposed strategies, the DFIG parameters have been intentionally changed such as the values of the resistances $R_{s}$ and $R_{r}$ are multiplied by 2 and the values of the inductances $L_{s}$ and $L_{r}$ are divided by 2 . Simulation results are presented in Figs. 14-18. Figs.14-15 shows the THD of stator current for the proposed strategies. It is found that seven-level DPC-SVM control reduced the THD compared to classical DPC (See Table 4).

Table 4. Comparative analysis of THD value

\begin{tabular}{|c|c|}
\hline DPC & Seven-level DPC-SVM \\
\hline $1.26 \%$ & $\mathbf{0 . 7 0} \%$ \\
\hline
\end{tabular}

Fig. 16 shows the active power responses of both the classical DPC control and seven-level DPC-SVM control scheme. It is found that the seven-level DPC-SVM exhibits smooth response and lesser ripples in active power as compared to the classical DPC strategy. Fig. 17 shows the zoom of the reactive power for classical DPC and proposed control scheme respectively. It is shown that the proposed strategy gives minimum reactive power ripples compared to classical DPC.

Electromagnetic torque response comparing curves are shown in Fig. 18. It can be seen that the torque ripple is significantly minimized when the seven-level DPC-SVM is in use. Thus, it can be concluded that the proposed sevenlevel DPC-SVM control scheme is more robust than the classical DPC one.
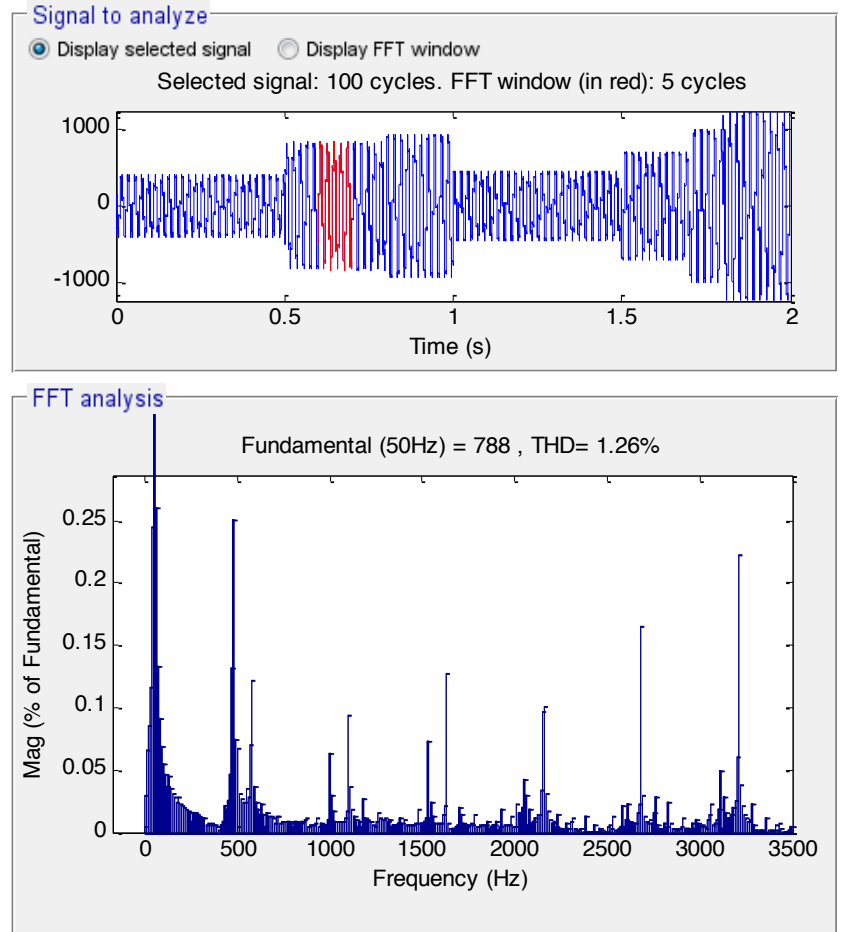

Fig. 14. Spectrum harmonic of rotor current (classical DPC)
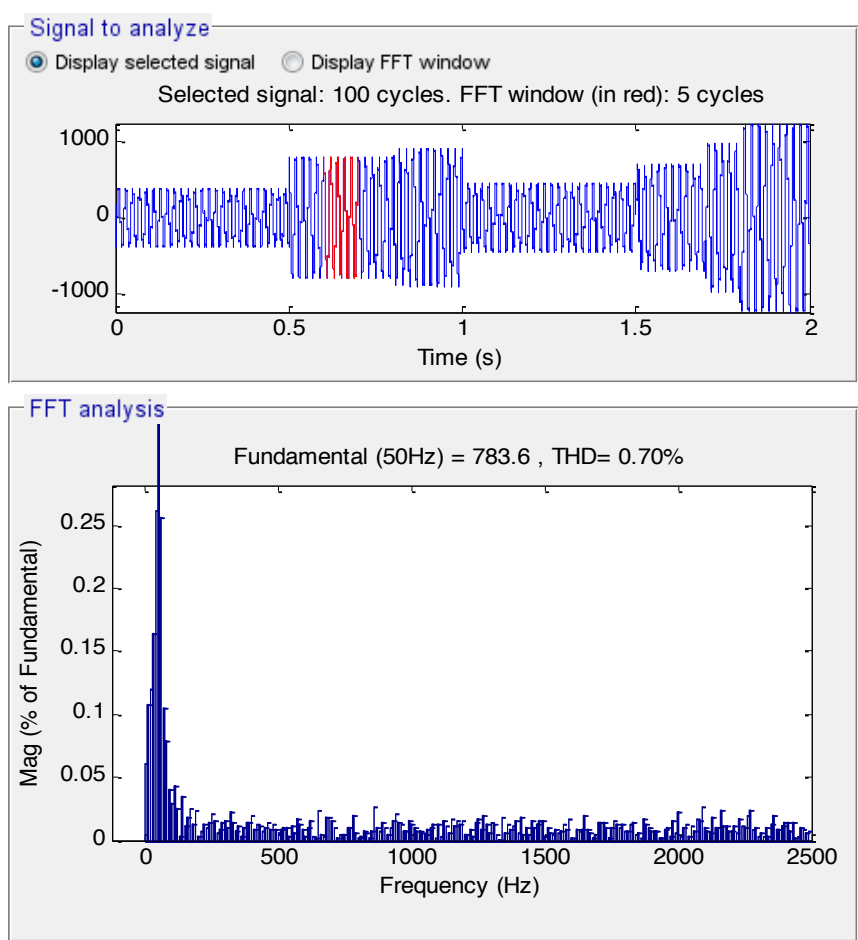

Fig. 15. Spectrum harmonic of rotor current (Seven-level DPCSVM) 
INTERNATIONAL JOURNAL Of SMART GRID

Habib Benbouhenni, Vol.3, No.2, June, 2019

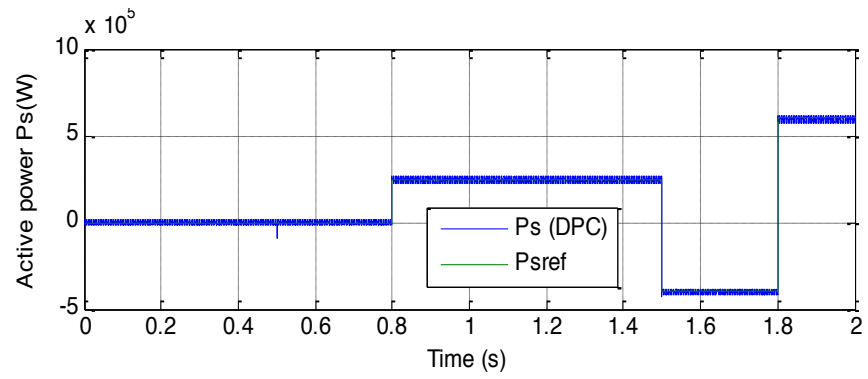

a)DPC

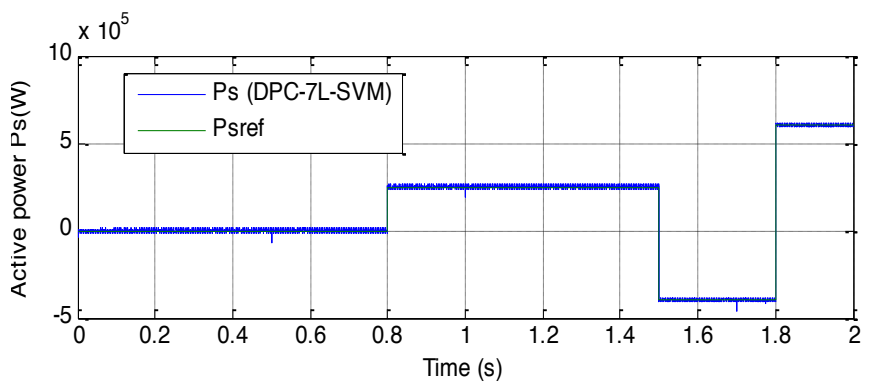

b)Seven-level DPC-SVM

Fig. 16. Active power (RT).

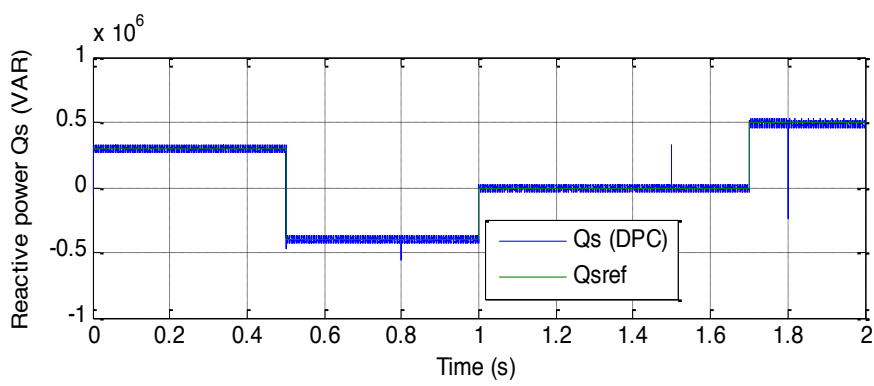

a)DPC

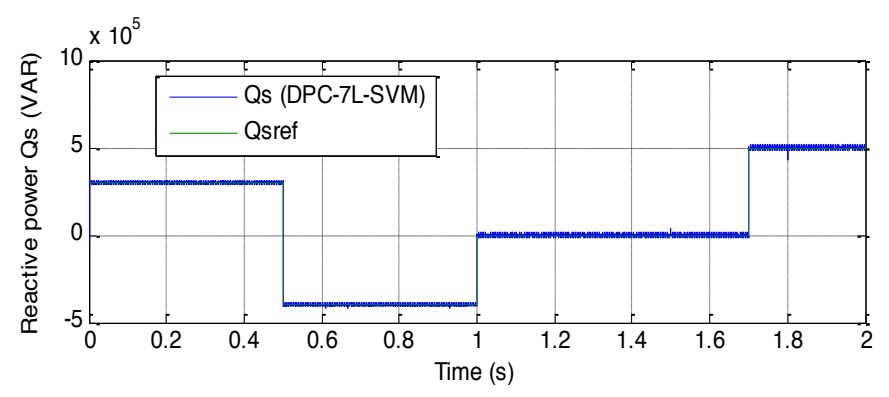

b)Seven-level DPC-SVM

Fig. 17. Reactive power (RT).

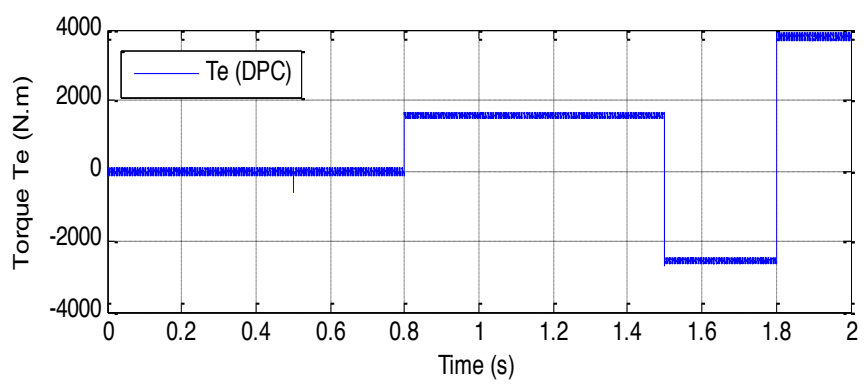

a)DPC

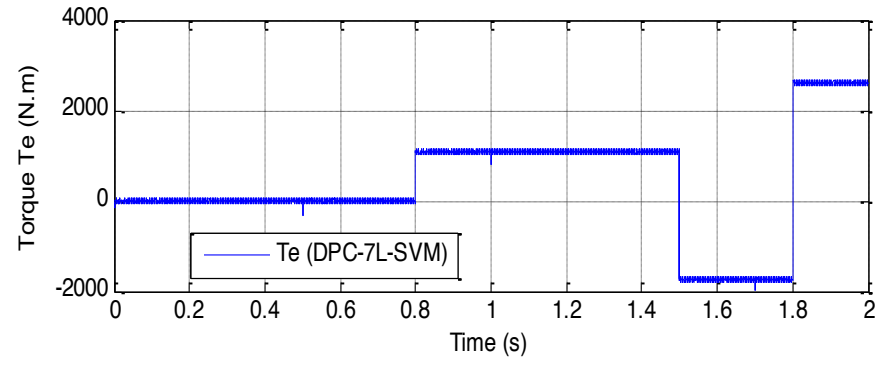

b) Seven-level DPC-SVM

Fig. 18. torque (RT).

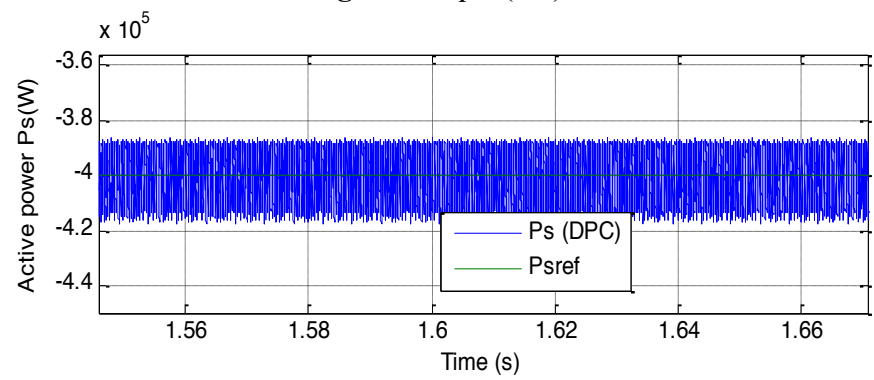

a)DPC



b)Seven-level DPC-SVM

Fig. 19. Zoom in the active stator power (RT).

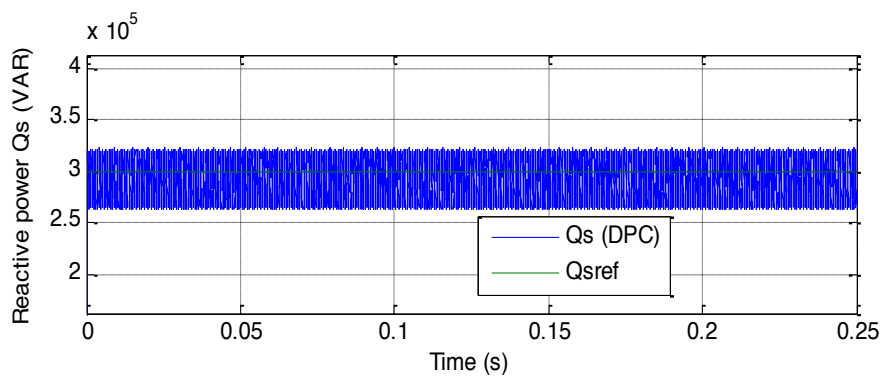

a)DPC

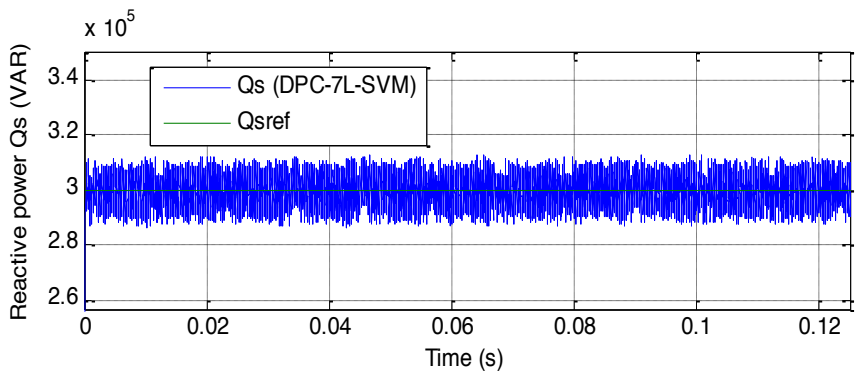

b) Seven-level DPC-SVM

Fig. 20. Zoom in the active stator power (RT). 


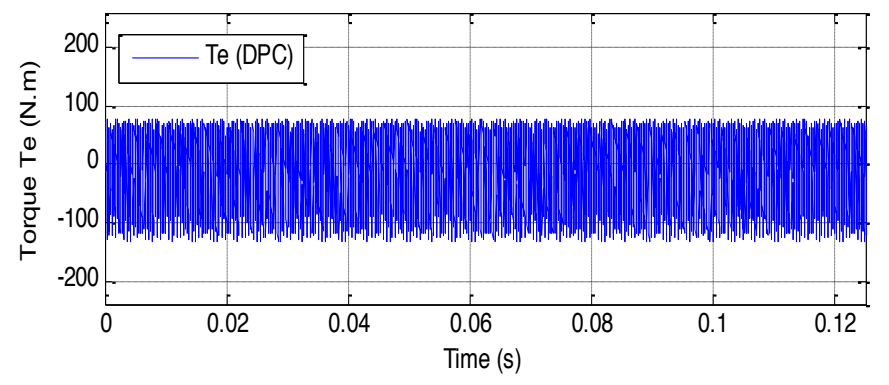

a)DPC

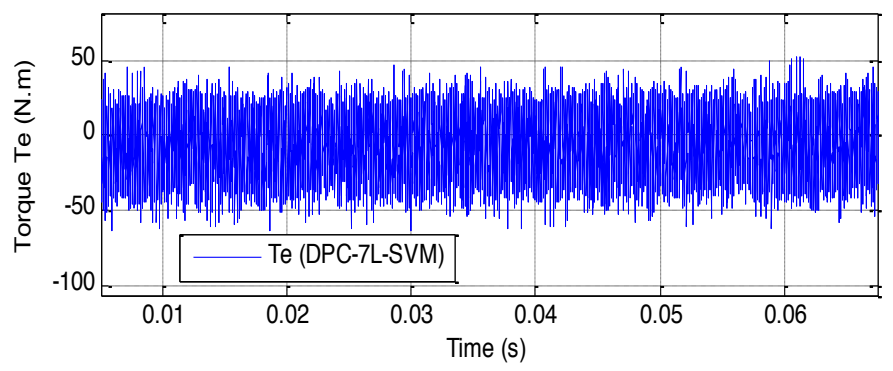

b)Seven-level DPC-SVM

Fig. 21. Zoom in the active stator power (RT).

\section{Conclusion}

A seven-level direct power control with space vector modulation for a wind power conversion systems equipped with DFIG controlled through power converter has been proposed in this work. This proposed control scheme is used to reduces the harmonic distortion of current/voltage and powers ripples of DFIG-based WTSs. The seven-level DPCSVM control scheme is a good candidate for controlling the WPCSs based on a DFIG interconnected to the grid.

\section{Appendix}

Table 5. Wind turbine parameters

\begin{tabular}{|l|c|l|}
\hline Blade radius & $\mathrm{R}$ & $35.25 \mathrm{~m}$ \\
\hline Number of blades & - & 3 \\
\hline Gearbox ratio & $\mathrm{G}$ & 90 \\
\hline Moment of inertia & $\mathrm{J}$ & $1000 \mathrm{Kg} \cdot \mathrm{m}^{2}$ \\
\hline Viscous friction coefficient & $\mathrm{fr}$ & $0.0024 \mathrm{~N} \cdot \mathrm{m} / \mathrm{s}$ \\
\hline Cut-in wind speed & - & $4 \mathrm{~m} / \mathrm{s}$ \\
\hline Cut-out wind speed & - & $\mathrm{m} / \mathrm{s}$ \\
\hline Nominal wind speed & $\mathrm{V}$ & $\mathrm{m} / \mathrm{s}$ \\
\hline
\end{tabular}

\section{References}

[1] Y. Djeriri, A. Meroufel, B. Belabbas, A. Massoum, «Three-level NPC voltage source based direct power control of the doubly fed induction generator at low constant switching frequency, » Revue des Energies Renouvelables, Vol. 16, No. 1, pp. 91-103, 2013.

[2] S. Massoum, A. Meroufel, A. Massoum, P. Wira, «A direct power control of the doubly-fed induction generator based on the SVM Strategy, » Elektrotehniški Vestnik, Vol. 84, No. 5, pp. 235240, 2017.

[3] H. Benbouhenni, «Neuro-sconde order sliding mode field oriented control for DFIG based wind turbine, » International Journal Of Smart Grid, Vol. 2, No. 4, pp. 209-217, 2018.

[4] H. Benbouhenni, «Comparative Study between Direct Vector Control and Fuzzy Sliding Mode Controller in Three-Level Space Vector Modulation Inverter of Reactive and Active Power Command of DFIG-Based Wind Turbine Systems, » International Journal Of Smart Grid, Vol. 2, No. 4, pp. 188-196, 2018.

[5] H. Benbouhenni, Z. Boudjema, A. Belaidi, « Indirect vector control of a DFIG supplied by a two-level FSVM inverter for wind turbine system, » Majlesi Journal of Electrical Engineering, Vol. 13, No. 1, pp. 45-54, 2019.

[6] H. Benbouhenni, «Direct vector control for doubly fed induction generator-based wind turbine system using five-level NSVM and two-level NSVM technique, » International Journal Of Smart Grid, Vol. 3, No. 1, pp. 25-32, 2019.

[7] H. Benbouhenni,, Z. Boudjema, A. Belaidi, «Using four-level NSVM technique to improve DVC control of a DFIG based wind turbine systems, » Periodica Polytechnica Electrical Engineering and Computer Science, Vol. 61, No. 3, 2019.

[8] L. Xu, P. Cartwright, « Direct active and reactive power control of DFIG for wind energy generation, » IEEE Transactions On Energy Conversion, Vol. 21, No. 3, pp. 750-758, 2006.

[9] A. Bouyekni, R. Taleb, Z. Boudjema, H. Kahal, « A second-order continuous sliding mode based on DFIG for wind-turbine-driven DFIG, » Elektrotehniški Vestnik, Vol. 85, No. 1-2, pp. 2936, 2018.

[10] Y. Djeriri, A. Meroufel, A. Massoum, Z. Boudjema, « Direct power control of a doubly fed induction generator based wind energy conversion systems including a storage unit, » Journal of Electrical Engineering, Vol.14, No.2, pp.1-8, 2014.

[11] M. V. Kazemi, A. S. Yazdankhah, H. M. Kojabadi, « Direct power control of DFIG based on discrete space vector modulation,» Renewable Energy, Vol. 35, pp. 1033-1042, 2010.

[12] S. M. Tavakoli, M. A. Pourmina, M. R. Zolghadri, «Comparison between different DPC methods applied to DFIG wind turbines, » International Journal of Renewable Energy Research, Vol. 3, No. 2, pp.446-452, 2013. 